(a)

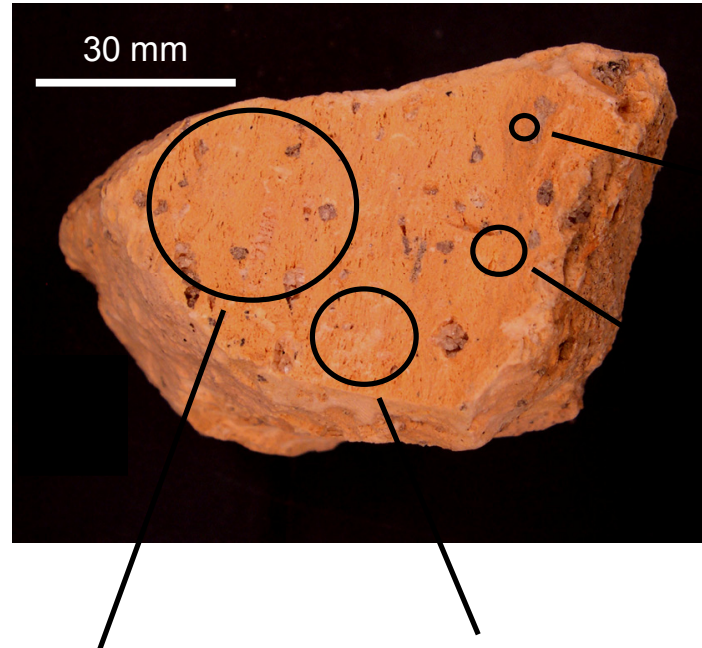

Run A

$\sim 10 \mathrm{~mm}$ diameter

$17 \mu \mathrm{m} /$ voxel

(b)

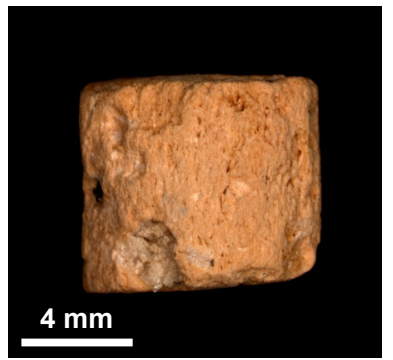

(c)

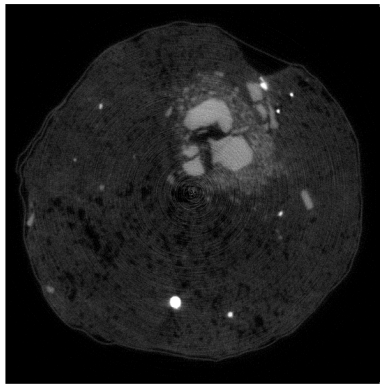

(d)
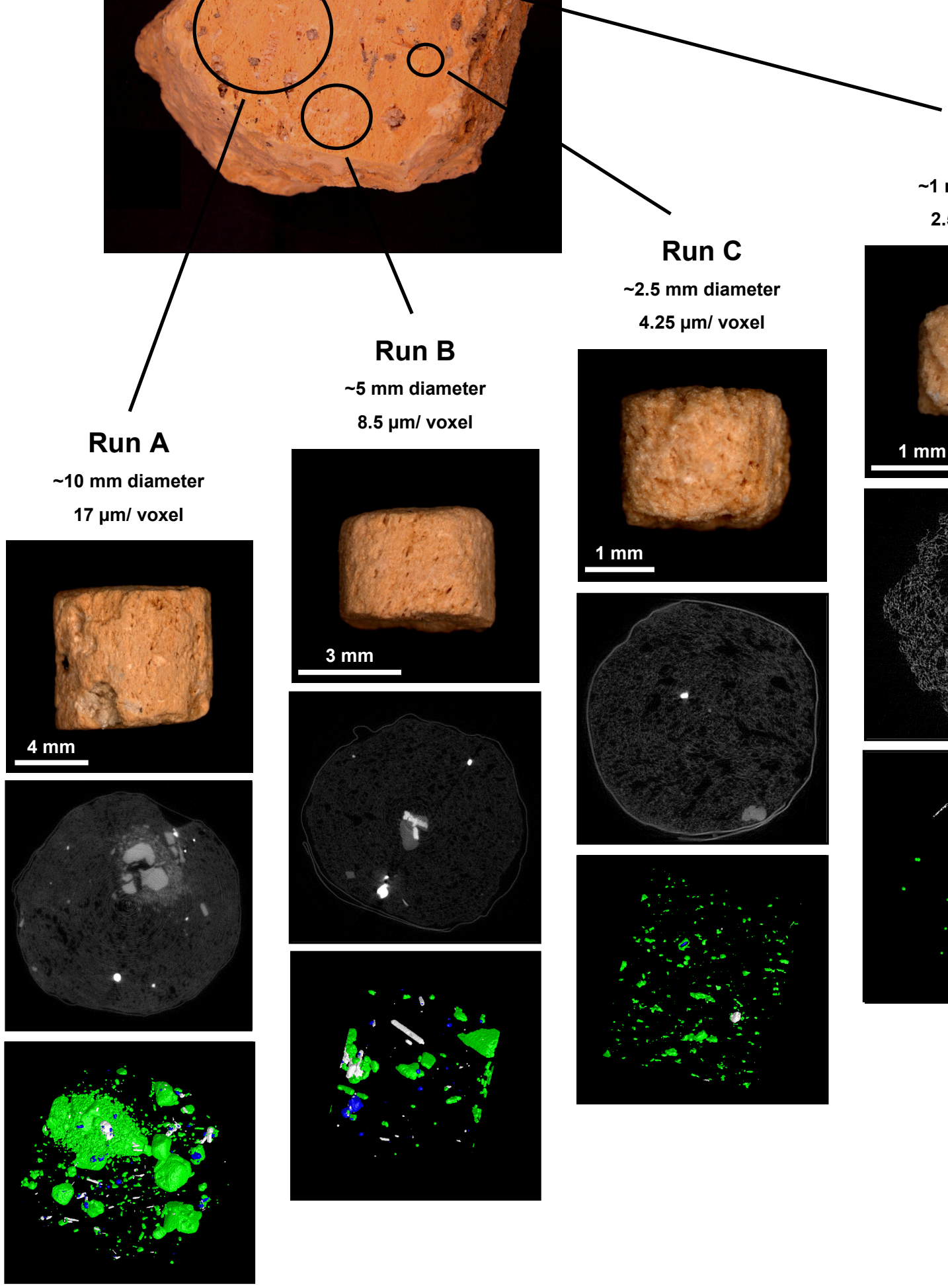

Run B

$\sim 5 \mathrm{~mm}$ diameter

$8.5 \mu \mathrm{m} /$ voxel

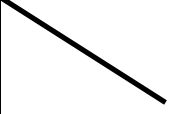

Run C

$\sim 2.5 \mathrm{~mm}$ diameter $4.25 \mu \mathrm{m} /$ voxel

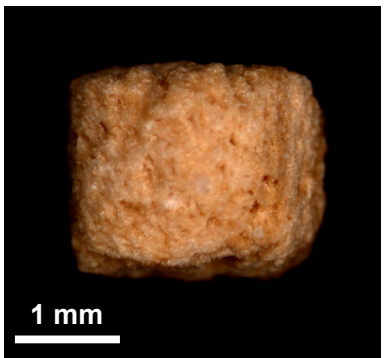

$3 \mathrm{~mm}$
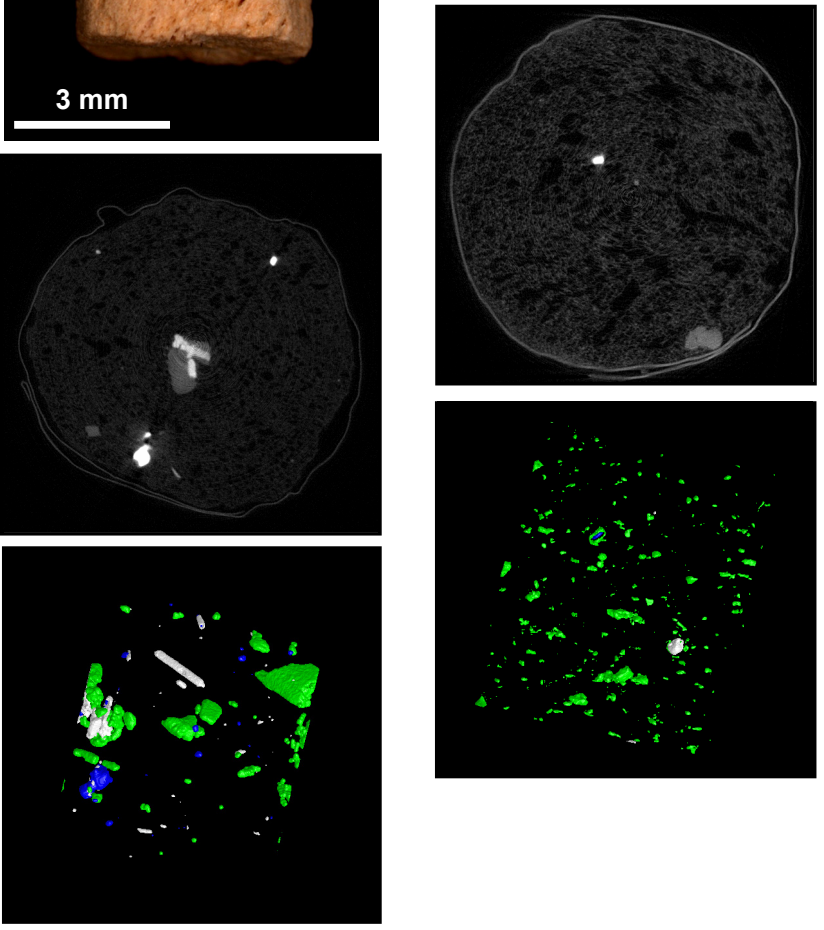

\section{Run D}

$\sim 1 \mathrm{~mm}$ diameter

$2.5 \mu \mathrm{m} / \mathrm{voxel}$
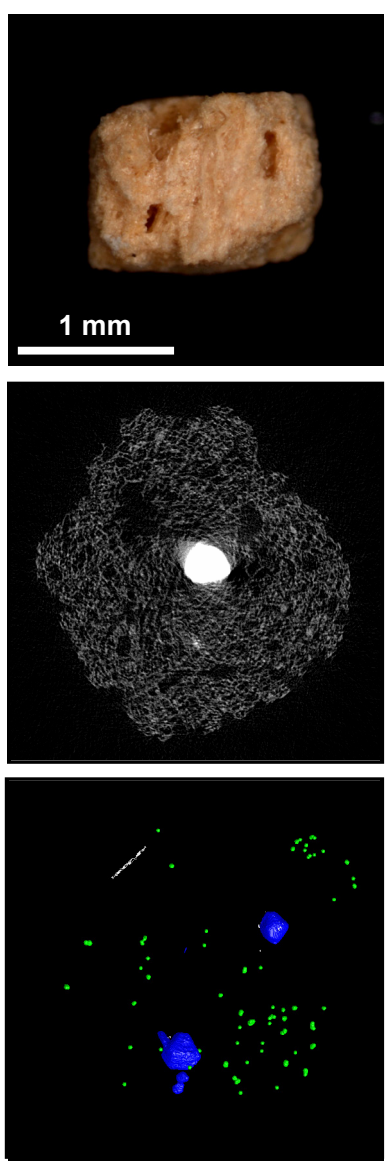